were collected only from the larder or passages adjacent to the kitchens; in no case were they taken from lavatories or from state-rooms. The general condition of the ship, which was almost new, was one of exceptional cleanliness, and thus afforded good conditions for the experiments. Dr. Morrell was of opinion that there was little danger except by contamination from the faeces of the infected insect.

One of his first experiments was to prove that should cockroaches fall into the dough which was being baked for bread the heat of the baking entirely destroyed the bacilli that were in the alimentary canal of the insect. With regard to infection with the colon bacillus he kept ar infected insect under the best antiseptic conditions he could compass until it had passed some undigested food. Of this un. digested food an emulsion was prepared, and cultures were made from it on bile-salt medium and in litmus-milk. $\Lambda$ fterwards special cultures were made in gelatine and peptone solutions. Incubation was conducted in all cases at $37^{\circ} \mathrm{C}$., and cultures were made from seventeen specimens. Five of these produced colonies of bacilli on the bile-salt medium, with subculture results as follows : Four produced acidity and clotting of milk, acid and gas in glucose, lactose and saccharose, and production of indol. But the bacilli did not liquefy gelatine, and were Gramnegative. One specimen produced gas in glucose and lactose and liquefied gelatine and coagulated milk. The former in its reaction corresponded with the Bacillus lactis aërogenes, the latter with Bacillus cloacae. In five cases greenish moulds of the aspergillus variety were found after inoculating litmus-milk.

Cockroaches will devour human sputum with avidity, and are frequently to be found in spittoons (or, as the more delicately minded American calls them, "cuspidors"), and it is interesting to know that after feeding the insects on infected sputum from a tuberculous patient, the tubercle bacilli are found in the faeces within twenty-four hours; two specimens which had been fed on staphylococci showed these pathogenic organisnıs in their faeces and in the cultures on agar-agar, which were obtained from these dejecta.

I have quoted largely from this important paper, and now propose to quote a good deal more, and thus I append Dr. Conyers Morrell's conclusion of the important experiments he conducted on the Union-Castle liner.

"The foregoing experiments, though insufficient in number to afford a basis for working out percentage results, are, I think, of some value, in that they prove the following facts:

"The common cockroach is able by contamination with its faeces (1) to bring about the souring of milk, (2) to infect food and milk with intestinal bacilli, (3) to transmit the tubercle bacillus, (4) to disseminate pathogenic staphy. lococci, (5) to transmit from place to place destructive moulds.

"These facts, taken in conjunction with the life-habits of the insect, lead to the conclusion that the cockroach is able to and may possibly play a small part in the dissemination of tuberculosis, and in the transmission of pyogenic organisms; that the insect is in all probability an active agent in the souring of milk kept in kitchens and larders; and that it is undoubtedly a very important factor in the distribution of moulds to food and to numerous other articles, especially when they are kept in dark cupboards and cellars where cockroaches abound. The distribution and numbers of the cockroach are rapidly increasing, and unless preventive measures are adopted the insectis likely in the course of time to become a very troublesome and possibly a very dangerous domestic pest." 2

REFERENCE.

1 The Transformation of Insects, by P. M. Duncan. London: Cassell, Petter, Galpin and Co., 1882. 2 British MEdical JockNaL, 1911, ii,
p. 1531 .

THE next Ophthalmological Congress will be held at Oxford on July 15th and 16th, when a discussion on industrial diseases and accidents will be opened by $\mathrm{Dr}$. Frank Shufflebotham. The honorary secretary of the congress is Mr. Bernard Cridland, of Wolverhampton.

THE Georgia State Sanitarium at Milledgeville has been chosen by the United States Government as a station for experimental work on pellagra. The patients will be separated and kept under special treatment-carried out inder the charge of two experts of the United States Public Health Service.

\section{A CASE OF TETANUS TREATED BY INJECTIONS OF CARBOLIC ACID.}

BY

\author{
PURVES STEWART, M.D., F.R.C.P., \\ AND \\ J. T. C. LAING, M.B., C.M.,
}

THE following case of tetanus appears worthy of record, in view of the fact that the disease, in spite of treatment by antitetanic serum, was steadily advancing. In such cases it may be useful to remember that we have other methods of treatment at our disposal.

The patient, aged 27, was an officer who, on October 27th, sustained several shell wounds-one in the right groin, another: in the right knee, a third, more severe, in the right hand. 'The wound of the hand became septic, and appears to have been the point of entrance of the tetanus infection. The patient came under the care of one of us on October 28th, in the Robert Lindsay hospital for officers.

On November 3rd-that is, seven days after the woundstetanic rigidity of the jaw muscles commenced. On the same evening he was given a subcutaneous injection of 1,500 units of antitetanic serum. The rigidity continued to spread, and extended to the abdominal and spinal muscles.

On November 4th 1,500 units of antitetanic serum were On November 4th 1,500 units of antitetanic serum were
injected intrathecally by $\mathrm{Mr}$. Tyrrell Gray. The foot of the injected intrathecally by Mr. Tyrrell Gray. The foot of the assist diffusion upwards of the serum. On November 5th a third dose of 1,500 units was given subcutaneously. The patient was also given full doses of bromide and chloral.

Notwithstanding the foregoing measures his condition became steadily worse, and on November 6th the rigidity of the jaws was extremely marked. The teeth could not be separated more than a quarter of an inch. The facial muscles were rigid, with risus sardonicus. The sterno-mastoids were tonically contracted, also the spinal and abdominal muscles, and slight stimuli produced typical tetanic spasms. The patient perspired profusely; his temperature was normal.

profusely; his temperature was normal.
At this stage it was decided to commence treatment by means of carbolic acid. Accordingly $2 \mathrm{c.cm}$. of a 5 per cent. solution were injected hypodermically into the abdominal wall every two hours. Improvement commenced on the same day. The spasms of the jaws, sterno-mastoids, and facial muscles steadily improved. The tetanic spasms diminished in frequency, and on November 7 th he had only one spasm, as compared with twelve on November 5 th. The carbolic injections on November 7th were reduced in frequency to four-hourly, but on November 8 th, owing to a slight recurrence of tetanic spasms, the injections were again increased to two-hourly for a couple of days. Tho spasms promptly diminished. From November 9th onwards spasms promptly diminished. 'From November 9th onwards and abdominal muscles were slower than the other muscles and abdominal muscles werc

On November li2th a diffuse, red, punctate rash appeared in both flanks, apparently a carbolic rash. The temperature te mained normal throughout. The urine, which was examined daily, never showed any pigmentation nor the slightest trace of albuminuria. From November 13th to November 18th the injections were reduced to four-hourly. They were theil stopped. The patient was discharged on December 5 th, completely cured.

This case exemplifies the efficiency of the carbolic acid treatment of tetanus, originally introduced by Baccelli some fifteen years ago. From a study of the statistics of published cases treated by antitetanic serum, the gross mortality varies from 78.9 per cent. in Permin's 199 cases to 61.8 per cent. in Iron's 225 cuses. On the other hand, the statistics of the carbolic acid treatment, as recorded by Baccelli, give a gross mortality of 17.4 per cent. in 190 collected cases. These figures are suggestive, and we consider it of the highest importance that cases of tetanus which may occur amongst our wounded officers and men during the present war should be given the chance of this treatment, which in no way supersedes tetanus antitoxin as a preventive, but appears to have certain advantages as a remedial agent once the disease has actually developed. It appears to us that the value of antitetanic serum lies chiefly in its preventive action.

THE New York Rockefeller Institute for Medical Research will receive $£ 40,0 \mathrm{C} 0$ under the will of $\mathrm{Mr}$. Henry Rutherford, to be apl iel to the investigation of cancer.

A Roentgen Ray Association, intended "to improve the practice and study of roen' genology and to form a closer association among roentgenolu ists or $x$-ray experts," has recently been founded in New York. The founders are Drs. George S. Dixon, I. Seth Hirsch, Adoniram Judson Quimby, William A. La Field, and Archibald P. Evans. 